Avalaible online: https://ejournal.iai-tribakti.ac.id/index.php/pgmi

Article doi: https://doi.org/10.33367/jiee.v3i1.1484

Submission: 2020-12-31 Review: 2021-02-11 Revision: 2021-03-27 Accepted: 2021-03-28

\title{
Upaya Peningkatan Pembelajaran Daring Mata Pelajaran Pendidikan Kewarganegaraan di Madrasah Ibtidaiyah
}

\section{Effort to Improve Online Learning on Civics Education in Islamic Elementary School}

\author{
Hidayat ${ }^{1}$, Heny Mulyani ${ }^{2}$, Tria Budiani Maris ${ }^{3}$, Tsania Fadilah ${ }^{4}$, \\ Wardah Anis 5, Wilda Nur Aeni Adawiyah 6 \\ 123456 Universitas Islam Negeri Sunan Gunung Djati Bandung \\ 1herihidayat@uinsgd.ac.id; ${ }^{2}$ henymulyani@uinsgd.ac.id; ${ }^{3}$ triamarisss@gmail.com; \\ ${ }^{4}$ tsaniafadiilah26@gmail.com; ${ }^{5}$ wardahanis97@gmail.com; \\ ${ }^{6}$ nuraeniwilda4@gmail.com
}

\begin{abstract}
This study seeks to find information related to the methods used in an effort to improve student achievement outcomes in online learning for civic education subjects at Madrasah Ibtidaiyah or Elementary Schools. In finding the information needed, researchers use a type of literature study research. Researchers reviewed several previous studies based on theories that were relevant to the problems found. The information obtained is then analyzed by referring to Miles and Hubberman where the information obtained is collected, processed and summarized. From the results of the analysis, it was found that using the mind mapping method and the STAD type cooperative model could improve learning outcomes as well as student creativity in Citizenship Education learning. Mind mapping can make it easier for students to understand a lesson that is recorded creatively, effectively, and efficiently in mapping their thoughts. This method really helps the learning process for Civics subjects, especially the Civics learning model is closely related to increasing children's creativity. Meanwhile, STAD should be grouped not randomly but according to the zoning of their respective houses. So that the presence or absence of a pandemic does not really affect learning with these methods.
\end{abstract}

Key Word: Online Learning, Citizenship Education, Mind Mapping, STAD

\begin{abstract}
Abstrak
Penelitian ini berupaya mencari informasi terkait metode yang digunakan dalam upaya meningkatkan hasil prestasi siswa pembelajaran daring untuk mata pelajaran pendidikan kewarganegaraan di Madrasah Ibtidaiyah atau Sekolah Dasar. Dalam mencari informasi yang dibutuhkan, peneliti menggunakan jenis penelitian studi kepustakaan. Peneliti mengkaji dari beberapa penelitian terdahulu berdasarkan teori yang relevan dengan
\end{abstract}


permasalahan yang ditemukan. Informasi didapat tersebut kemudian dianalisis dengan mengacu kepada Miles dan Hubberman dimana infomasi yang didapat dikumpulkan, diolah, dan disimpulkan. Dari hasil analisis diperoleh bahwa dengan menggunakan metode mind mapping dan model kooperatif tipe STAD bisa meningkatkan hasil pembelajaran sekaligus kreativitas siswa pada pembelajaran Pendidikan Kewarganegaraan. Dengan mind mapping dapat mempermudah pemahaman peserta didik dalam suatu pembelajaran yang dicatat dengan kreatif, efektif, dan efisien dalam memetakan pikiran-pikirannya. Metode ini sangat membantu proses pembelajaran untuk mata pelajaran PKn, apalagi model pembelajaran PKn erat kaitannya dengan peningkatan kreativitas anak. Sementara untuk STAD hendaknya dikelompokan tidak secara acak namun sesuai zonasi rumahnya masing-masing. Sehingga ada ataupun tidak adanya pandemi, tidak terlalu mempengaruhi pembelajaran yang dilakukan.

\section{Kata Kunci: Pembelajaran Daring, Pendidikan Kewarganegaraan, Mind Mapping, STAD}

\section{Pendahuluan}

Tidak dapat dipungkiri covid telah memengaruhi segala aspek kehidupan. Tak terkecuali untuk aspek pendidikan. Pendidikan yang semula dilakukan dengan tatap muka secara langsung tentu menjadi hal yang sulit diwujudkan. Salah satu solusi yang bisa diterapkan adalah dengan menggunakan pembelajaran daring. Pembelajaran daring pun tidak akan berjalan dengan lancar jika tidak dipersipakan secara matang. Dalam pembelajaran daring salah satu hal yang harus diperhatikan dalam pembelajarannya adalah metode pembelajaran yang digunakan sang guru. Dari segi bahasa terdapat beberapa makna mengenai metode. Dalam Bahasa Inggris yaitu Method. Dan dalam Bahasa Yunani yaitu Methodos yang terdiri dari meta yang artinya sesudah atau melampaui, dan hodos artinya cara atau jalan. Dari makna ini secara istilah adalah suatu cara kerja yang sudah tersistem untuk mempermudah suatu kegiatan agar tercapainya tujuan yang sudah ditentukan. Atau cara melaksanakan kaidahkaidah yang jelas dan tegas untuk menacapai ilmu pengetahuan ${ }^{1}$.

Metode pembelajaran yaitu suatu cara yang digunakan guru atau siswa untuk memperoleh sebuah informasi baik berupa fakta, konsep, dan data dalam proses pembelajaran yang dijadikan menjadi suatu strategi. Seorang guru hendaknya pandai dalam memilih metode pembelajaran yang tepat sesuai dengan kondisi siswa dan materi yang akan disampaikan ${ }^{2}$

Metode dan media memiliki hubungan yang erat dalam proses pembelajaran. Seorang guru harus meningkatkan kemampuannya untuk mengefektifkan suasana belajar dengan

\footnotetext{
${ }^{1}$ LPKN, Kamus Besar Ilmu Pengetahuan (Jakarta: Lembaga Pengkajian Kebudayaan Nasional Nusantara, 2006).

2 Syaiful Sagala, Konsep dan Makna

Pembelajaran (Bandung: Alfabeta, 2003).

el Bidayah: Journal of Islamic Elementary Education Volume 3, Nomor 1, Maret 2021 
bantuan media pembelajaran ${ }^{3}$. Dengan metode pembelajaran yang tepat, maka hasil pembelajaran pun akan maksimal. Namun, dalam setiap metode memiliki kelebihan dan kekurangnnya masingmasing. Oleh sebab itu, kita selaku guru harus bisa mengkombinasikan beberapa metode untuk menetralisir kekurangankekurangan yang ada.

Dalam masa pandemi ini, semua aktivitas harus dilakukan di rumah. Begitupun dengan belajar. Menjadi tantangan baru untuk para pendidik agar tetap bisa menyampaikan ilmu dengan baik dengan metode-metode pembelajaran baru yang dapat diterima oleh siswa. Teknologi di Era 4.0 sudah sangat berkembang dengan baik dan maju secara cepat. Dengan adanya teknologi, pembelajaran pun terus maju mengikuti arus zaman. Perkembangan ilmu pengetahuan pun dijadikan sebagai alat bantu dalam kegiatan pembelajaran. Dengan teknologi ini, kita bisa mendapatan segala sesuatu dengan cepat, seperti mencari bahan ajar untuk proses pembelajaran yang akan dilaksanakan. Disamping menjadi pembantu dalam mencari bahan ajar, teknologi ini pun menjadi hambatan, apalagi bagi para pendidik yang sudah menua. Namun bagaimana lagi, zaman terus berganti dan proses belajar mengajar harus tetap dilakukan. Keterampilan belajar menggunakan teknologi digital akan sangat membantu untuk lebih cepat mengenal teknologi serta

\footnotetext{
${ }^{3}$ Agus Suprijono, Cooperative Learning, Teori \& Aplikasi PAIKEM (Surabaya: Pustaka Belajar, 2009).

${ }^{4}$ Rijal Darusman, "Penerapan Metode Mind Mapping (peta pikiran) Untuk meningkatkan el Bidayah: Journal of Islamic Elementary Education Volume 3, Nomor 1, Maret 2021
}

mendapatkan kemampuan berteknologi pada pendidik dan peserta didik, bahkan pendidik pun dengan mudah mengembangkan bahan pembelajaran. Menurut pendekatan ilmu pengetahuan memberikan gambaran bahwa kita sebagai peserta didik harus mampu mengikuti perkembangan ilmu pengetahuan dan teknologi digital.

Dalam pembelajaran daring ini pun, pendidik harus kreatif dalam memilih metode pembelajaran yang akan digunakan selama pembelajaran berlangsung. Karena bagaimanapun, semangat belajar siswa ketika dirumah dan di sekolah itu berbeda. Dengan menggunakan mind mapping bisa membantu mengembangkan daya berpikir yang kreatif pada siswa dengan menyusun ide-ide pikiran menjadi sebuah konsep ${ }^{4}$. Kooperatif tipe Student Team Achievement Divisions (STAD) dengan cara mengelompokan siswa sesuai gender, ras, etnis, dan kemampuan. Pertama-tama mereka mempelajari bersama kelompoknya, kemudian diuji secara individual dengan memberikan kuis berupa soal ${ }^{5}$. Serta masih banyak metode pembelajaran lainnya yang bisa menjadi rekomendasi untuk model pembelajaran daring PKn di MI pada masa pandemi ini.

Kami memilih pembahasan ini karena kami menyesuaikan dengan situasi yang ada. Pandemi Covid-19 pada saat ini sedang melanda seluruh negara di dunia, khususnya Indonesia yang

Kemampuan Berpikir Kreatif Matematik Siswa SMP," Infinity Journal 3, no. 2 (2014): 164-173. ${ }^{5}$ Robert E. Slavin, Cooperative Learning, Teori, Riset, dan Praktik (Bandung: Nusa Media, 2008). 
Upaya Peningkatan Pembelajaran Daring Mata Pelajaran Pendidikan Kewarganegaraan di Madrasah Ittidaiyah Oleh: Hidayat, Heny Mulyani, Tria Budiani Maris, Tsania Fadilah, Wardah Anis, Wilda $\mathcal{N} u r$ Aeni, dan Adawiyah

mana seluruh aktivitas yang kepustakaan sebelumnya dengan meberhubungan dengan sosial harus ngumpulkan informasi dan data secara dirumahkan. Seperti bekerja dari rumah atau sering disebut Work From Home (WFH) dan belajar dari rumah atau sering disebut dengan daring.

Pendidikan yang terus maju adalah pendidikan yang terus mengikuti alur zamannya, Menyesuaikan dengan situasi dan kondisi. Karena kondisi saat ini adalah pandemi, maka pendidikan yang harus kita tingkatkan adalah pendidikan di masa pandemi. Ini menjadi kondisi yang baru dan sulit untuk para guru dan siswa, sehingga kami ingin membahas tentang upaya peningkatan pembelajaran daring dalam mata pelajaran Pendidikan Kewarganegaraan di Madrasah Ibtidaiyah. Semoga jurnal kami bisa menjadi rekomendasi setiap guru dalam upaya peningkatan pembelajaran daring di Sekolah Dasar atau Madrasah Ibtidaiyah ini.

\section{Metode}

Penelitian ini adalah tipe penelitian studi pustaka dimana kegiatan penelitian dilakukan dengan cara mengumpulkan informasi dan data dengan bantuan berbagai macam material yang ada di perpustakaan atau sumber dari internet yang berkaitan dengan masalah yang ingin dipecahkan. Metode yang digunakan dalam penelitian ini adalah dengan mencari kitab dan tulisan ilmiah terkini. Peneliti mencari referensi teori yang relavan dengan permasalahan yang ditemukan, berupa tulisan atau kata tertulis dari seseorang. Dalam mengumpulkan data peneliti mencari literatur atau mendalam melalui beberapa buku dan hasil jurnal penelitian sebelumnya untuk mendapatkan landasan teori dan jawaban mengenai masalah yang kami teliti.

Setelah data terkumpul kemudian data diolah, dan disimpulkan berdasarkan analisis data yang dikemukakan oleh Miles dan Hubberman. Dalam menganalisis data peneliti memilih topik berdasarkan fenomena yang ada yaitu pembelajaran daring pada masa pandemi. peneliti mengumpulkan sumber data informasi dari buku, jurnal dan hasil laporan penelitian terdahulu yang sesuai dengan tema, setelah itu kami membaca sumber data yang telah kami kumpulkan secara mendalam agar mendapatkan ide-ide yang baru. Setelah membaca semua data, kami mengolah dan menganalisis agar menjadi suatu kesimpulan dan menyusun laporan sesuai dengan sistematika penulisan yang berlaku.

\section{Temuan dan Pembahasan \\ Temuan penelitian}

Sistem pembelajaran daring atau yang sering disebut dengan pembelajaran dalam jaringan merupakan sistem pembelajaran tanpa tatap muka secara langsung baik oleh guru dan siswa ataupun oleh dosen dan mahasiswa tetapi pembelajarannya dilakukan secara online menggunakan jaringan internet. Dalam pembelajaran daring baik guru maupun dosen harus bisa memastikan kegiatan belajar dan mengajar tetap berjalan dengan baik dan efektif meskipun siswa ataupun 
Vpaya Peningkatan Pembelajaran Daring Mata Pelajaran Pendidikan Kewarganegaraan di Madrasah Ibtidaiyah Oleh: Hidayat, Heny Mulyani, Tria Budiani Maris, Tsania Fadilah, Wardah Anis, Wilda Nur Aeni, dan Adawiyah

mahasiswa tetap berada dirumah. Pembelajaran secara daring juga merupakan pembelajan yang sangat singkat waktunya serta sangat ekonomis. Dan pembelajaran daring juga dapat memudahkan siswa untuk menerima bahan ajar karena dapat dilakukan setiap saat dan juga bisa dilakukan secara berulang-ulang. Maka dari itu pembelajaran daring ini menjadi kesempatan bagi seluruh pelajar untuk menuntut ilmu secara sungguhsungguh.

Pembelajaran PKn di MI merupakan satu mata pelajaran yang wajib dipelajari sejak jaman SD/MI karena bertujuan untuk mengembangkan kecerdasan, agar memahami negara dalam dimensi spiritual, dalam dimensi rasional, emosional dan juga sosial. Dan Pembelajaran PKn di MI juga dapat membangun karakteristik siswa agar menjadi warga negara yang patuh akan tata tertib dan aturan yang berlaku di Indonesia serta mengembangkan peserta didik untuk ikut berpartisipasi dalam menjadi warga negara yang baik.

Pembelajaran yang berorientasi kepada siswa (student centered approach) salah satu metode yang diduga mampu membuat suasana pembelajaran yang menarik, memotivasi siswa dan menyenangkan ketika siswa mempelajari materi melalui Mind Map (peta pikiran).

Mind Mapping atau peta konsep adalah suatu teknik penyusunan catatan, gagasan atau ide-ide pikiran yang dapat digunakan untuk mempermudah pemahaman peserta didik dalam suatu pembelajaran yang dicatat dengan kreatif, efektif, dan efisien dalam memetakan pikiran-pikiran nya. Selain itu juga, mind mapping biasanya menggunakan kata kunci bebas, simbol, gambar dan biasanya menggambarkan secara kesatuan dengan menggunakan teknik pohon. Setiap ranting dari pohon yang dibuat adalah sub bahasan dari konsep yang dipeta kan dari sebuah materi.

Metode ini pun membantu para siswa untuk mudah menghafal dan memahami materi yang telah disampaikan. Namun sayangnya, dengan metode ini hanya siswa yang aktif yang bisa lebih diuntungkan. Namun murid yang kurang aktif dalam menjelaskan suatu materi yang telah ia buat dengan metode Mind Mapping dapat mengekspresikannya dengan membuat Mind Mapping se-kreatif mungkin sesuai versinya masing-masing.

Selanjutnya adalah metode STAD atau Student Team Achievement Division adalah metode pembelajaran yang kooperatif dengan mengelompokan beberapa siswa dan mereka berdiskusi bersama teman sekelompoknya. Kemudian setelah itu mereka akan diuji secara perseorangan melalui soal yang diberikan oleh gurunya. Kooperatif learning adalah model pembelajaran yang melibatkan kelompok kecil dengan jumlah siswa empat sampai lima orang sehingga pembelajaran antar anak didik bisa bekerja sama dalam mengerjakan tugas-tugas terstruktur (Slavin, 2008). Model pembelajaran kooperatif tidak sama dengan kerja kelompok lainnya, melainkan terdapat unsur-unsur yang menjadi pembeda adalah saat pembagian kelompok yang tidak asal-asalan, 
Upaya Peningkatan Pembelajaran Daring Mata Pelajaran Pendidikan Kewarganegaraan di Madrasah Ibtidaiyah Oleh: Hidayat, Heny Mulyani, Tria Budiani Maris, Tsania Fadilah, Wardah Anis, Wilda Nur Aeni, dan Adawiyah

entah itu sesuai dengan jenis kelamin, ras, budaya, etnis dan kemampuan 6 .

Materi yang bisa diterapkan pada metode ini adalah mengamalkan sumpah pemuda, dimana siswa diharapkan memiliki jiwa Nasionalisme yang tinggi serta pembentukan karakter yang berhubungan dengan kehidupan yang mereka laksanakan baik di lingkungan sekolah maupun di lingkungan masyarakat, dan aspek yang dikembangkan adalah aspek kepribadian, etika, dan moral. Dengan menggunakan metode STAD siswa dapat menumbuhkan proses pembelajaran dengan cara tradesional yaitu dengan cara berpikir dan bertindak secara demokratis, memiliki kooperatif, mau mengikuti pembelajaran secara aktif, dan menghormati perbedaan dalam masyarakat yang multibudaya.

\section{Pembahasan}

Metode Mind Mapping sangat membantu proses pembelajaran untuk mata pelajaran PKn, apalagi model pembelajaran PKn erat kaitannya dengan peningkatan kreativitas anak. ${ }^{7}$ Misalnya, dalam penjelasan tata negara Indonesia dapat dibantu dengan metode mind Mapping ini. Anak akan lebih paham struktur dan susunan dari tata negara Indonesia kita ini. Dalam materi Garuda Pancasila pun anak dapat membuat Mind Mapping untuk setiap makna yang ada dalam tubuh Garuda

\footnotetext{
${ }^{6}$ Anita Lie, Cooperative Learning: Menerapka Cooperative Learning di Ruang-ruang Kelas (Jakarta: PT Grasindo, 2008).

${ }^{7}$ Heri Hidayat dkk., "Penerapan Metode Mind Mapping untuk Meningkatkan Kreativitas Pada Pembelajaran Pendidikan Kewarganegaraan," Jurnal Pendidikan Islam: Islamic Educational 98
}

Pancasila. Hal ini pun menambah daya tarik siswa dalam belajar, apalagi Mind Mapping yang dibuat penuh warna dan kreasi lainnya. Namun di masa pandemi ini semuanya terbatasi ${ }^{8}$. Anak tidak bisa berbagi dan bertukar fikiran langsung di kelas. Mungkin anak hanya bisa membuat di rumah nya masing-masing dan difotokan ke guru nya masingmasing. Namun hal ini pun tidak mengurangi kemampuan kreativitas anak. Apalagi ketika seorang guru memutuskan untuk mengirim hasil Mind Mapping dari setiap siswa dalam satu grup kelas, maka siswa yang lain ketika melihat hasil temannya bagus, ia akan termotivasi membuat Mind Mapping ini lebih bagus lagi menurut versi nya.

Penerapan Mind Mapping pada masa pandemi Covid-19 yaitu kegiatan belajar mengajar dialihkan dari sekolah menjadi belajar di rumah. Siswa yang diberikan tugas rumah sebagai cara belajar di rumah. Namun, hal itu justru membebani siswa dan orang tua sehingga diperlukan cara untuk meningkatkan semangat belajar para siswa. Penerapan kegiatan belajar dengan metode Mind Mapping dikatakan mampu meningkatkan hasil belajar siswa karena merupakan cara yang paling mudah untuk memasukan informasi ke dalam otak sekaligus mengambil informasi tersebut melalui proses berfikir. Penggunaan teknik gambar pada saat membuat Mind Mapping berasal dari

Institution Concerning Islamic Education 21, no. 1 (2020): 38-50.

8 Wahyu Aji Fatma Dewi, "Dampak COVID-19 terhadap Implementasi Pembelajaran Daring di Sekolah Dasar," Edukatif : Jurnal Ilmu

Pendidikan 2, no. 1 (2020): 55-61. 
Vpaya Peningkatan Pembelajaran Daring Mata Pelajaran Pendidikan Kewarganegaraan di Madrasah Ibtidaiyah Oleh: Hidayat, Heny Mulyani, Tria Budiani Maris, Tsania Fadilah, Wardah Anis, Wilda Nur Aeni, dan Adawiyah

pikiran manusia yang bermanfaat untuk menyediakan kunci-kunci umum sehingga membuka potensi otak dalam meningkatkan hasil belajar.

Belajar dengan teknik visual Mind Mapping dilakukan dengan cara meringkas materi ke dalam bentuk virtual gambar dengan kolaborasi animasi untuk memudahkan siswa mengingat materi. Namun demikian, tetap meningkatkan pembelajaran melalui pendampingan dalam membuat Mind Mapping sebelum siswa dapat dilepas sendiri. Harapannya, teknik ini dapat terus dikembangkan dan dilaksanakan sampai pandemi Covid-19 berakhir sebagai perubahan belajar secara virtual yang sulit dilaksanakan di daerah pedesaan karena berbagai faktor. Ini juga bukan tanpa alasan, sebab teknik Mind Mapping juga melatih kreatifitas siswa yang sedang belajar, orang tua yang mendampingi dan guru yang mengajar.

Mata pelajaran Pkn yang mempunyai misi membina nilai, moral, dan norma secara utuh bulat dan berkesinambungan. Tujuan Pkn adalah untuk membentuk warga negara yang baik, yaitu yang tahu, mau dan sadar akan hak dan kewajibannya. Pkn memiliki karakter yang berbeda dengan mata pelajaran lainnya. Hal ini bisa dilihat berdasarkan ciri-ciri atau hal-hal yang bersifat khusus, yang pada prinsipnya Pkn lebih dari larangan aspek moral (afektif) tanpa meninggalkan aspek yang lain. Untuk mencapai sasaran dan target tersebut, dalam pelaksanaan pembelajaran metode mind mapping yang diperlukan peralatan tulis dan sumber belajar agar dapat dilihat dan mudah digunakan oleh siswa. Media pembelajaran dalam PKn harus dapat menstimulus proses lahirnya proses pembelajaran yang aktif dan kreatif.

Penerapan Mind Mapping dapat meningkatkan kreativitas siswa karena cara kerja pemetaan pikiran melibatkan cara kerja dasar otak yang tersusun lebih bercabang-cabang seperti pohon. Pola ini dapat mempermudah proses mengingat pada setiap apa yang diukur. Siswa dapat tertarik untuk membuat gambar-gambar atau warna-warna pada Mind Mapping agar terlihat lebih bagus dan menarik. Dalam proses pembelajaran di kelas siswa sangat antusias mengikuti proses pembelajaran menggunakan metode Mind Mapping, karena mereka lebih bebas berkreasi dalam tugas yang diberikan guru dan lebih mudah untuk memecahkan permasalahan yang diberikan guru. Kreativitas siswa setelah menggunakan metode Mind Mapping mengalami peningkatan dalam proses dan hasil pembelajaran yang dilakukan. Jadi, ada ataupun tidak pandemi ini tidak terlalu mempengaruhi metode Mind Mapping dalam mata pelajaran PKn di MI ini.

Pada masa pandemi ini, pembelajaran harus dilakukan di rumah namun tidak menghilangkan esensi dari sekolah itu sendiri dan tujuan pembelajaran pun diharapkan bisa tercapai. Melalui pembelajaran daring kita bisa menerapkan metode pembelajaran STAD, dimana para siswa dikelompokan tidak secara acak namun sesuai zonasi rumahnya masing-masing. Hal ini dilakukan agar terjadinya pembelajaran yang aktif antar teman sebaya, me- 
Upaya Peningkatan Pembelajaran Daring Mata Pelajaran Pendidikan Kewarganegaraan di Madrasah Ibtidaiyah Oleh: Hidayat, Heny Mulyani, Tria Budiani Maris, Tsania Fadilah, Wardah Anis, Wilda Nur Aeni, dan Adawiyah

numbuhkan nilai-nilai sosial, belajar mendengarkan pendapat orang lain, dan bekerja sama dalam memecahkan suatu masalah pembelajaran.

Adapun langkah-langkah yang dilakukan saat metode ini diterapkan pada pembelajaran daring yaitu pertama membagi kelompok kecil sesuai zonasi rumahnya yang terdekat. Kedua, mereka berdiskusi tentang materi yang telah diberikan, baik secara bertatap muka sesuai dengan protokol kesehatan atau bisa menggunakan aplikasi yang mendukung bisa terjadinya diskusi seperti video call namun tetap dalam pengawasan orang tua. Ketiga, guru akan memberikan evaluasi berupa kuis kepada perseorangan. Keempat, guru bisa memberikan apresiasi kepada kelompok yang memiliki nilai rata-rata tertinggi.

Dengan menerapkan metode kooperatif tipe STAD ini, hasil pembelajaran siswa akan meningkat. ${ }^{9}$ Kemampuan mengingat materi akan lebih mudah ketika siswa itu sendiri aktif dalam mengemukakan pendapatnya dan mendengarkan pendapat dari teman sebaya, daripada hasil ceramah dari guru yang biasa dilakukan saat pembelajaran. Dalam hal ini juga, guru dituntut kreatif dalam pembelajaran metode kooperatif tipe STAD. Apalagi di saat pademi ini pembelajaran menggunakan teknologi dan harus menyiapkan sarana pembelajaran tambahan

\footnotetext{
${ }^{9}$ Aspan R. H. Mahmud, Bonifasius Saneba, dan Jamaludin, "Meningkatkan Hasil Belajar Siswa Pada Pembelajaran PKn Melalui Pendekatan Pembelajaran Kooperatif Tipe STAD Kelas IV SD Inpres Koyoan," Jurnal Kreatif Tadulako Online 5, no. 1 (2017): 44-52.
}

yang membantu dalam penyampaian materi dan penerapan metode kooperatif tipe STAD ini.

\section{Kesimpulan}

Mind mapping atau peta konsep adalah suatu teknik penyusunan catatan, gagasan atau ide-ide pikiran yang dapat digunakan untuk mempermudah pemahaman peserta didik dalam suatu pembelajaran yang dicatat dengan kreatif, efektif, dan efisien dalam memetakan pikiran-pikirannya. Metode ini sangat membantu proses pembelajaran untuk mata pelajaran PKn, apalagi model pembelajaran PKn erat kaitannya dengan peningkatan kreativitas anak.

Sedangkan metode STAD atau Student Team Achievement Division adalah metode pembelajaran yang kooperatif dengan mengelompokan beberapa siswa dan mereka berdiskusi bersama teman sekelompoknya. Model pembelajaran kooperatif tidak sama dengan kerja kelompok lainnya, melainkan terdapat unsur-unsur yang menjadi pembeda adalah saat pembagian kelompok yang tidak asal-asalan, namun berdasarkan jenis kelamin, ras, budaya, etnis dan kemampuan ${ }^{10}$. Untuk model ini para siswa dikelompokan tidak secara acak namun sesuai zonasi rumahnya masing-masing. Jadi, ada ataupun tidak pandemi ini tidak terlalu mempengaruhi pembelajaran metode mind mapping dan model pembelajaran

10 Tukiran, Banani Ma'mur, dan Eko Priyanto, "Model Pembelajaran Student TeamsAchievment Division (STAD)," Seminar Nasional Hasil Penelitian dan Pengabdian Pada Masyarakat IV Tahun 2019 "Pengembangan Sumberdaya menuju Masyarakat Madani Berkearifan Lokal," 366-362.

el Bidayah: Journal of Islamic Elementary Education Volume 3, Nomor 1, Maret 2021 
Upaya Peningkatan Pembelajaran Daring Mata Pelajaran Pendidikan Kewarganegaraan di Madrasah Ibtidaiyah Oleh: Hidayat, Heny Mulyani, Tria Budiani Maris, Tsania Fadilah, Wardah Anis, Wilda Nur Aeni, dan Adawiyah

STAD dalam mata pelajaran PKn di MI ini.

\section{Daftar Pustaka}

Darusman, Rijal. "Penerapan Metode Mind Mapping (peta pikiran) Untuk meningkatkan Kemampuan Berpikir Kreatif Matematik Siswa SMP." Infinity Journal 3, no. 2 (2014): 164-73.

Dewi, Wahyu Aji Fatma. "Dampak COVID-19 terhadap Implementasi Pembelajaran Daring di Sekolah Dasar." Edukatif: Jurnal Ilmu Pendidikan 2, no. 1 (2020): 55-61.

Hidayat, Heri, Heny Mulyani, Ajeng Siti Fatimah, Amallia Sholihat, dan Ana Zulfia Latifah. "Penerapan Metode Mind Mapping untuk Meningkatkan Kreativitas Pada Pembelajaran Pendidikan Kewarganegaraan." Jurnal Pendidikan Islam: Islamic Educational Institution Concerning Islamic Education 21, no. 1 (2020): 38-50.

Lie, Anita. Cooperative Learning: Menerapka Cooperative Learning di Ruang-ruang Kelas. Jakarta: PT Grasindo, 2008.

LPKN. Kamus Besar Ilmu Pengetahuan. Jakarta: Lembaga Pengkajian Kebudayaan Nasional Nusantara, 2006.

Mahmud, Aspan R. H., Bonifasius Saneba, dan Jamaludin. "Meningkatkan Hasil Belajar Siswa Pada Pembelajaran PKn Melalui Pendekatan Pembelajaran Kooperatif Tipe STAD Kelas IV SD Inpres Koyoan." Jurnal Kreatif Tadulako Online 5, no. 1 (2017): 44-52.

Sagala, Syaiful. Konsep dan Makna Pembelajaran. Bandung: Alfabeta, 2003.
Slavin, Robert E. Cooperative Learning, Teori, Riset, dan Praktik. Bandung: Nusa Media, 2008. Suprijono, Agus. Cooperative Learning, Teori \& Aplikasi PAIKEM.

Surabaya: Pustaka Belajar, 2009.

Tukiran, Banani Ma'mur, dan Eko Priyanto. "Model Pembelajaran Student Teams-Achievment Division (STAD)." Seminar Nasional Hasil Penelitian dan Pengabdian Pada Masyarakat IV Tahun 2019 "Pengembangan Sumberdaya menuju Masyarakat Madani Berkearifan Lokal," 366 362M. 